\title{
Effect of Pakistani Parental Role and Teachers' Role on the Neuroticism Personality of Students
}

* Dr. Syed Afzal Shah, Assistant Professor (Corresponding Author)

** Dr. Habib Elahi, Assistant Professor

*** Dr. Sadaf Naz, Assistant Professor

\begin{abstract}
This survey research study was carried out in Hazara Division, Khyber Pakhtunkhwa, at secondary schools to investigate the impact of parental role and teachers' role on the neuroticism personality trait of students. Fourteen hundred and thirty-eight (1438) grade 10 students were selected through stratified random sampling techniques from the population of the study. Two questionnaires; one for a parental role, and another for teachers' roles were developed. The third questionnaire was adopted to probe information about neuroticism personality trait. Results showed that Parents play their role by providing emotional support to their children while teachers maintain a secure environment classroom. Adolescents' neurotic tendencies are decreased due to emotional support from parents. Similarly motivation of teachers reduces these neurotic tendencies in adolescents. In the same way, the neurotic trend in male students is reduced through the emotional support of parents, and the motivation of teachers.
\end{abstract}

Keywords: Aggression of Parents, Emotional Support of Parents, Security in the Classroom, the Motivation of Teachers

\section{Introduction}

An individual's organized, constant, and distinctive set of qualities is called his / her personality (Bhagat, \& Nayak, 2014). Hereditary and environmental aspects like family as well as culture establish these qualities of personality (Begum, 2016). One of the extensively used personality models is the Big Five personality model and it plays its significant function since decades of research studies both in school as well as home (Kyllonen, Lipnevich, Burrus, \& Roberts., 2014). One of the five factors/ qualities of personality is Neuroticism. The high neuroticism is characterized by anger, recklessness, sadness (depression), and hopelessness (Aldinger, Stopsack, Ulrich, Appel, Reinelt, Wolff, Grabe, Lang, \& Barnow., 2014) while the low neuroticism is characterized by serenity, selfassurance (Kiarie, Maru, \& Cheruiyot., 2017). This high or low neuroticism of adolescents is formed by the environment of the family (Kågesten, Gibbs, Blum, Moreau, Chandra-Mouli, Herbert, \& Amin., 2016). Parental attitude forms the personality of their children (Rossi, \& Rossi., 2018). So it can be deduced that the actions of parents towards their kids are one feature of the environment that shapes their personality.

\section{Objectives of the Study}

1. To find out the effect of parental role on the trait of neuroticism personality of students

2. To find out the effect of teachers' role on the trait of neuroticism personality of students

3. To find out the comparative effect of parental role and teachers' role on the trait of neuroticism personality of male and female students

\section{Hypotheses of the Study}

1. Parental and teachers' role has a positive effect on the neuroticism factor of personality.

2. Parental emotional support has a negative effect on the neuroticism factor of personality.

3. Classroom security has a positive effect on the neuroticism factor of personality.

4. The motivation of teachers has a negative effect on the neuroticism factor of personality.

\footnotetext{
* Department of Education, The University of Haripur, Haripur, Pakistan Email: afzal_kakakhel@ yahoo.com

** Department of Education, Hazara University Mansehra, Pakistan

*** Department of Education, Hazara University Mansehra, Pakistan
} 


\section{Literature Review}

Different types of behaviors are displayed by parents towards their children. Parental aggression is one of the important behaviors of parents. Issues have been discussed upon the influence of aggression of parents on the personality of the family including children. From the making inquiries, findings suggested that whether short term or long term, parental aggression has effects on personality like depression (Fite, Rubens, Preddy, Raine, \& Pardini., 2014) and anxiety (Kowalski, \& Giumetti, 2017). One feature of parental aggression is called psychological aggression. This type of aggression is intended to cause psychological pain to the child. Spoken/ symbolic anger, expressive violence, mistreatment, and mental maltreatment, are the words interchangeably for psychological aggression (Vissing, Straus, Gelles, \& Harrop. 1991). Verbal or non-verbal, active or passive, maybe the forms of this communicative act. For example, name-calling or horrible comments, colliding something like with the door may be displayed in this form of aggression. The techniques like the use of oral/representative or together both types of aggression interrupt the child's psychological world and the child may face internalizing problems such as depression, isolation as well as adjustment problems both in babyhood and teenage years (Soenens, Vansteenkiste, Luyten, Duriez, \& Goossens., 2005). Additionally, these aggressive behaviors of parents affect the scholastic accomplishment of students as well. Studies have found the significant effects of harsh parenting on the scholastic accomplishment of students. For example, it is found that controlling or authoritarian parenting leads to poor academic achievement (Chao, 1994). The reason is that children, whose parents use aggressive practices, cannot concentrate on their studies which ultimately leads to their lower academic achievement (Rizvi, \& Najam, 2014). This aggressive behavior of parents reflects the family conflict which is a major risk factor of poor academic performance of children (Bahrassa, Syed, \& Lee. 2011). Few studies have been reported on the role of Pakistani aggressive parents and their effects on children. For example, Syed and Hussein (2009) found that $42.3 \%$ of the children have conduct problems. Such behavioral and upsetting troubles were described to be $34.0 \%$ and teachers place them under the "abnormal" category (Engle, Black, 2008). So it is concluded that there are two types of aggressive behaviors displayed by parents. One type is physical aggression and the other is the psychological aggression. Both types of aggressive behaviors have significant effects on developing the neurotic tendencies among the children. It is very difficult for them to concentrate on their studies due to their psychological problems.

The other extreme side of parental action is the emotional support of parents towards their kids. This embracing has positive consequences such as social and personal growth (Rossi, \& Rossi, 2018) and improvement of resilience among children (Tol, Song, \& Jordans., 2013).

The further aspect of the atmosphere which affects the personality of students in school and teacher affects the personality of students. Trained teachers build the personality of students in a positive way (Bastian, McCord, Marks, \& Carpenter, 2015) because they adopt a balance for those who are at high risk of failure (Good, \& Lavigne., 2017). Moreover, they apply rules and procedures for the effective management of classes (Austin, \& Omomia., 2014). That is why they have classes in control (Glackin., 2018).

The parental behavior and teachers' attitude is discussed thoroughly at the international level to explore the area under discussion but in Pakistan, only a few lines of investigation have been carried out. For example, Iqra et al. (2017) performed research on parental personality, the atmosphere of family, and personality of Pakistani adolescents where they explored the personality of adolescents is greatly influenced by the personality of parents. In the same way, Najma and Kausar $(2011)^{17}$ researched fathers' acceptance-rejection, fathers' attachment, and socio-emotional regulation of adolescents where they found that due to parental attachment, hostility and depression are decreased.

\section{Methodology}

\section{Research Design}

This study was guided by the quantitative research methodology. It involved the Survey questionnaires to gather information from the field which focused on the variables of the study.

\section{Population and Sample of the Study}

The population of the study consisted of class ten students from Hazara Division, Khyber Pakhtunkhwa, Pakistan. 1438 (fourteen hundred and thirty-eight) students represented the sample of this study selected through a stratified random sampling technique. This sample was selected to 
represent at least ten percent of the population. The students who passed the ninth-grade examination and promoted to $10^{\text {th }}$ grade were included in the study while the students who participated in the pilot study were excluded from the study.

From Hazara Division three districts namely district Abbottabad, district Haripur, and District Mansehra were approached to select eighty-four schools. Security in the classroom, and the motivation of teachers represented the variables of teachers' role in the questionnaire. Relevant literature was studied thoroughly to construct nineteen (19) items for the questionnaire for teachers' role. Security in a classroom comprised of ten items whereas the motivation of teachers had nine (09) items. Big Five factors of personality represented the questionnaire for exploring the personality of students. Only one variable (factor) namely Neuroticism was selected and adopted though formal permission from the author of the questionnaire. The other four variables of the questionnaire were extraversion, conscientiousness, openness, and agreeableness. Dr. Tom Buchanan developed this forty-one (41) items questionnaire by taking ideas from the international personality item pool (Goldberg, 1999).

\section{Data Collection Tools}

Two questionnaires were developed for inquiring the answers of students. Between the two surveys, the initial one about parental behavior consisted of two aspects namely aggressive behavior of parents, emotional support from parents. The other developed questionnaire focused on security in the classroom, and the motivation of teachers. The two questionnaires were formed due to the consultation of correlated writing. Through the expert view, the questionnaires were validated. The reliability coefficient of parental aggressive behavior was 0.930 , for the emotional support of parents it was 0.85 , for security in the classroom was 0.74 , and for teachers' motivation, it was 0.690 . The consistency coefficient for the neuroticism feature of personality was 0.55 . All these reliability coefficients were established as a result of a pilot study which was performed on a hundred (100) students.

The surveys regarding the parental role, teachers' role, and personality feature namely neuroticism were converted from English to Urdu and from Urdu, they were translated back to English. This method of translation is called the back-translation method. The purpose of applying this method was to ensure that original and translated questionnaires convey the same meaning.

Neurotic personality trait, parental role, teachers' role were used for gathering data from the selected students. The three questionnaires were represented on five-point Likert scales. The Likert scale about the survey of parental role had the options of "Never", "sometimes", "Don't know", "often", and "Always". Similarly, the Likert scale about the questionnaire of teachers' role had the options of "Never", "sometimes", "Don't know", "often", and "Always". While 'very inaccurate' up to some extent accurate', 'neither accurate nor inaccurate', 'accurate to some extent', 'very accurate', where the options for personality trait namely neuroticism. All the options of the questionnaires were assigned numbers i.e. 1 to 5. "Never" was assigned 1 number, and "Always" was assigned number 5. The positive items in the questionnaire were assigned numbers in this style while the style for the negative items was reversed.

Hundred students were selected for conducting a pilot study. These students were selected from various schools. It was aimed to conduct a pilot study for removing the ambiguities in the questionnaires. So the translated versions of the questionnaires were distributed among the 100 students. It was ensured that the students understand these questionnaires.

For the collection of data, eighty-four (84) secondary schools of district Mansehra, district Haripur, and district Abbottabad were approached. Neuroticism characteristics of personality, teachers' role, and parents' role were exercised to explore the information. After permission from the respective Heads of the schools, students were selected by simple random sampling technique.

\section{Data Analysis}

The collected information was scrutinized by using frequency, percentage, mean (M), standard deviation (S.D), and regression analysis. Frequency along with percentage was used to depict the demographic information of the students. Mean as well as standard deviation were used to describe the variables (aggression of parents, emotional support of parents, security in classroom, and motivation of teachers) of the study while regression analysis used to explore the effect of parental role and teachers' role on neuroticism factor of personality. 


\section{Results}

Statistical tools like frequency, percentage, mean, standard deviation and regression analysis used for the analysis of the information are discussed in this component of the article. The information collected was analyzed through mean (M), Standard Deviation (S. D), and regression analysis. Objective wise analysis of the data is presented accordingly.

\section{Table 1}

Demographic depiction of the learners

\begin{tabular}{ll}
\hline No. of students (Sector wise) & N $(\%)$ \\
\hline Public & $725(50.4)$ \\
Private & $713(49.6)$ \\
No. of students (Location-wise) & \\
Rural students & $718(49.9)$ \\
Urban students & $720(50.1)$ \\
Mothers' qualification & \\
Inter Pass & $1356(94.2)$ \\
B. A/ B. Sc and above & $82(5.8)$ \\
Fathers' Qualification & $1076(74.8)$ \\
Inter Pass & $362(21.6)$ \\
Bachelor and above & \\
\hline
\end{tabular}

Table 1 depicts the demographic information of the students who took part in this research study. Table 1 shows that $725(50.4 \%)$ of the students represented the public sector schools, while 713 $(49.6 \%)$ of the students represented the private secondary schools. From a location point of view, 718 $(49.9 \%)$ of the students were selected from rural area secondary schools while $720(50.1 \%)$ of the students were selected from urban secondary schools.

\section{Table 2}

Depiction of parental role and teachers' role

\begin{tabular}{ll}
\hline Variables & Mean \pm S.D \\
\hline Aggression of Parents & $03.8 \pm 01.0$ \\
Emotional Support of Parents & $3.8 \pm 0.6$ \\
Security in Classroom & $3.9 \pm 0.8$ \\
Motivation of Teachers & $3.8 \pm 0.7$ \\
\hline
\end{tabular}

Table 2 shows up the Arithmetic mean, and standard Deviation of aggressive behavior of parents, their emotional support, security in the classroom, and motivation of teachers. The mean value of the emotional support of parents $(3.8 \pm 0.6)$ is the highest among parental roles. The mean value of security in the classroom $(3.9 \pm 0.8$ is the highest among the teachers' roles.

Table 3

Impact of the role of parents and the role of teachers on Neurotic personality trait

\begin{tabular}{llllll}
\hline & Beta & S. E & beta & t value & P-value \\
\hline Aggression of parents & 0.0130 & 0.02 & 0.02 & 00.59 & 0.56 \\
Emotional Support of Parents & -0.0920 & 0.03 & -0.08 & -2.95 & $0.00^{*}$ \\
Security in Classroom & -0.0640 & 0.03 & -0.08 & -2.23 & $0.03^{*}$ \\
Motivation of Teachers & -0.0450 & 0.02 & -0.050 & -1.86 & 0.06 \\
\hline R square $=0.0250 \quad$ Adj. square $=0.0220$ & F statistic $=9.27$ & $\alpha=0.000$ & & \\
\hline
\end{tabular}

Table 3 illustrates the mathematical value of $\mathrm{R}$ square is 0.0250 which shows that 2.50 percent variability in the neurotic personality trait of students is explained by the aggressive behavior of parents, emotional support given by parents to children, security in the classroom, and motivation given by teachers to students. The value of Beta of aggression of parents (0.0130) depicts not a considerable impact on the neuroticism personality trait. The $t$ value of 0.59 confirms this result with a 0.56 value of $p$. The value of Beta of emotional support of parents (-0.0920) depicts a considerable and significant impact on the neuroticism personality trait. The value of the beta of security in the classroom (-0.0640) depicts a significant impact on the neuroticism personality trait.

\section{Table 4}

Effect of parental role and teachers' role on the trait of neuroticism personality of male students

\begin{tabular}{llllll}
\hline & B & S. E & beta & t value & p-value \\
\hline (Constant) & 4.25 & 0.21 & & 20.46 & 0.00 \\
Aggression of parents & 0.0040 & 0.03 & 0.01 & 0.15 & 0.88 \\
Emotional Support of parents & -0.18 & 0.04 & -0.16 & -3.99 & $0.00 *$
\end{tabular}




\begin{tabular}{llllll} 
security in classroom & -0.06 & 0.04 & -0.080 & -1.59 & 0.11 \\
Motivation of teachers & -0.071 & 0.03 & -0.080 & -2.06 & $0.04 *$ \\
\hline
\end{tabular}

Table 4 illustrates the value of $\mathrm{R}$ square is 0.048 which shows that 4.8 percent variability in the neurotic personality trait of students is explained by the aggressive behavior of parents, emotional support given by parents to children, security in the classroom, and teachers' motivation to students. The value of beta for emotional support of parents (-0.18) depicts a significant impact on the neuroticism personality trait. The value of Beta of the motivation of teachers $(-0.071)$ depicts a significant impact on the neuroticism personality trait.

\section{Table 5}

Effect of parental role and teachers' role on the trait of neuroticism personality of female students

\begin{tabular}{llllll}
\hline & B & S. E & beta & t value & p-value \\
\hline Aggression of parents & -0.03 & 0.03 & -0.04 & -0.89 & 0.38 \\
Emotional Support of parents & -0.02 & 0.04 & -0.01 & -0.35 & 0.72 \\
security in classroom & -0.07 & 0.04 & -0.08 & -1.67 & 0.09 \\
Motivation of teachers & -0.024 & 0.04 & -0.03 & -0.69 & 0.49
\end{tabular}

Table 5 also illustrates the mathematical value of $\mathrm{R}$ square is 0.010 which shows that 1.0 percent variability in the neurotic personality trait of students is explained by the aggressive behavior of parents, emotional support given by parents to children, security in the class, and motivation given by teachers to students. The model is fit but no factor of parental role and teachers' role significantly affects the neuroticism factor or personality.

\section{Discussion}

The current research endeavor aimed at exploring the effect of aggressive behavior of parents, emotional support provided by them to their children, maintaining security in the classroom, and providing motivation to them on their neuroticism characteristic of personality of class ten (10) students. One of the results of this research was that the aggression of parents had the highest mean among the variables of a parental role. This result indicated a higher aggressive attitude of parents towards their children. The value of aggressive behavior of parents is although greater, greater variations in standard deviation are shown. This indicated that a great proportion of parents do not rely on aggressive behavior in dealing with their children. In the same way, security in the classroom indicates the highest mean among the two variables of teachers' roles. It can be implied from this result that the teachers to a large amount focus on the environment of the classroom that is free from bullying and harsh words from teachers and they also try to make a pleasant and secure classroom environment.

A positive effect was shown by the aggression of parents on the neuroticism personality trait. It can be implied from results that aggression in parents may be due to tendencies of neuroticism in parents which may be transferred into their children. It can also be inferred that due to genetic dispositions there may be similarities in personality traits as well coupled with the effect of modeling (Bandura, \& Walters., 1977). Children facing less emotional support and greater punishing control from their parents indicate a greater point of psychological illness like anxiety and depression in the later stage of life (Havighurst, \& Kehoe, 2017).

Parents using emotional support in their behavior resulted in decreasing neuroticism personality. It reflects that the personality of the children can be developed positively by the parental emotional support. Ultimately the students become productive members of the family. Otherwise, home is made in trouble by the unstructured attitude of parents (Elder, 2018). It is because personality traits like maturity in the children are developed due to the positive home environment (FlensborgMadsen, Revsbech, Sørensen, \& Mortensen., 2014). The result findings show that relationship experiences do not affect the personality of students (Asendorpf, Van Aken., 2003).

The results of the study further highlighted that security in the classroom has a profound influence on the neuroticism personality trait. From this result, it can be inferred that rapport between students and teachers is an indication of a secure classroom which ultimately helps in reducing depression and anxiety and boosts self-esteem (Taylor, Oberle, Durlak, \& Weissberg, 2017). It is a fact that a conducive classroom environment has a positive influence on the character of the students (Subawo., 2016). 
Results further show that emotional support of parents significantly decrease neuroticism personality attribute. It is undoubtedly a fact that the personality of children is boosted up by the provision of psychological support from parents (Weinberg, \& Gould., 2018).

The neuroticism personality trait of male students is profoundly negatively affected by the motivation of teachers. It indicates that teachers with positive personality traits like extraversion and openness can better motivate their students which helps in the reduction of neurotic tendencies in children.

\section{Conclusion}

Parents play their role by providing emotional support to their children while teachers maintain a secure environment classroom. Adolescents' neurotic tendencies are decreased due to emotional support from parents. Similarly, the motivation of teachers reduces these neurotic tendencies in children. In the same way, the neurotic trend in students is reduced through the emotional support of parents, and the motivation of teachers.

\section{Limitations of the Study}

From some female schools, data could not be collected through the personal visit of the researcher but requested the concerned Principals/ Heads for assigning the duty to other female teachers for data collection from the female students. It was due to cultural barriers that the researcher could not personally enter the female schools.

The range and choice of response of students might have been limited due to the use of only questionnaires as data collection tools.

\section{Suggestions}

Since the emotional support of parents helps in reducing neurotic tendencies in students, it is recommended that parents should politely correct the mistakes of their children; they should avoid blaming and continuously use encouragement on their academic effort.

References

Aldinger, M., Stopsack, M., Ulrich, I., Appel, K., Reinelt, E., Wolff, S., ... \& Barnow, S. (2014). Neuroticism developmental courses-implications for depression, anxiety, and everyday emotional experience; a prospective study from adolescence to young adulthood. $B M C$ psychiatry, 14(1), 210.

Asendorpf, J. B., \& Van Aken, M. A. (2003). Personality-relationship transaction in adolescence: Core versus surface personality characteristics. Journal of personality, 71(4), 629-666.

Austin, O. O., \& Omomia, T. A. (2014). Perceived impact of classroom management on effective teaching: A study of five schools in education district 11, Lagos State, Nigeria. European Scientific Journal, 10(22).

Bahrassa, N. F., Syed, M., Su, J., \& Lee, R. M. (2011). Family conflict and academic performance of first-year Asian American undergraduates. Cultural Diversity and Ethnic Minority Psychology, 17(4), 415.

Bandura, A., \& Walters, R. H. (1977). Social learning theory (Vol. 1). Englewood Cliffs, NJ: Prentice-hall.

Bastian, K. C., McCord, D. M., Marks, J. T., \& Carpenter, D. (2015). Do personality traits impact beginning teacher performance and persistence. Chapel Hill, NC: University of North Carolina.

Begum, T., \& Huque, A. U. (2016). Parents' personalities and their expectations about a child's development. Universal Journal of Psychology, 4(5):222-7.

Bengtson, V. L., \& Allen, K. R. (2009). The life course perspective applied to families over time. In Sourcebook of family theories and methods (pp. 469-504). Springer, Boston, MA.

Chao, R. K. (1994). Beyond parental control and authoritarian parenting style: Understanding Chinese parenting through the cultural notion of training. Child Development, 65(4), 1111-1119.

Elder, G. H. (2018). Children of the great depression. Routledge.

Elhamid, A. A., Howe, A., \& Reading, R. (2009). Prevalence of emotional and behavioral problems among 6-to 12-year-old children in Egypt. Social psychiatry and psychiatric epidemiology, 44(1), 8.

Engle, P. L., \& Black, M. M. (2008). The effect of poverty on child development and educational outcomes. Annals of the New York Academy of Sciences, 1136, 243. 
Fite, P. J., Rubens, S. L., Preddy, T. M., Raine, A., \& Pardini, D. A. (2014). Reactive/proactive aggression and the development of internalizing problems in males: The moderating effect of parent and peer relationships. Aggressive Behavior, 40(1), 69-78.

Flensborg-Madsen, T., Revsbech, R., Sørensen, H. J., \& Mortensen, E. L. (2014). An association of adult personality with prenatal and early postnatal growth: the EPQ lie-scale. BMC psychology, 2(1), 8 .

Glackin, M. (2018). 'Control must be maintained': exploring teachers' pedagogical practice outside the classroom. British journal of sociology of education, 39(1), 61-76.

Goldberg, L. R. (1999). A broad-bandwidth, public domain, personality inventory measuring the lower-level facets of several five-factor models. Personality psychology in Europe, 7(1), 7-28.

Good TL, Lavigne AL (2017). Looking in classrooms. Routledge;.

Havighurst, S., \& Kehoe, C. (2017). The role of parental emotion regulation in parent emotion socialization: Implications for intervention. In Parental stress and early child development (pp. 285-307). Springer, Cham.

Kågesten, A., Gibbs, S., Blum, R. W., Moreau, C., Chandra-Mouli, V., Herbert, A., \& Amin, A. (2016). Understanding factors that shape gender attitudes in early adolescence globally: A mixed-methods systematic review. PloS one, 11(6).

Kiarie, M. A. W., Maru, L. C., \& Cheruiyot, T. K. (2017). Leader personality traits and employee job satisfaction in the media sector, Kenya. The TQM Journal. 29(1):133-46

Kowalski RM, Giumetti GW (2017). Bullying in the digital age. In cybercrime and its victims. Routledge.

Kyllonen, P. C., Lipnevich, A. A., Burrus, J., \& Roberts, R. D. (2014). Personality, motivation, and college readiness: A prospectus for assessment and development. ETS Research Report Series, 2014(1), 1-48.

Najam, N., \& Kausar, R. (2012). Father Acceptance-Rejection, Father Involvement, and SocioEmotional Adjustment of Adolescents in Pakistan. Journal of Behavioural Sciences, 22(1), 122.

Ramidha, V. P. (2019). Study on the need to implement mentorship for the emotional development among medical students. Journal of Education Technology in Health Sciences, 6(2), 40-43.

Rizvi, S. F. I., \& Najam, N. (2014). Parental psychological abuse toward children and mental health problems in adolescence. Pakistan journal of medical sciences, 30(2), 256.

Rossi AS, Rossi PH (2018). Of human bonding: Parent-child relations across the life course. Routledge.

Soenens, B., Vansteenkiste, M., Luyten, P., Duriez, B., \& Goossens, L. (2005). Maladaptive perfectionistic self-representations: The mediational link between psychological control and adjustment. Personality and individual differences, 38(2), 487-498.

Subawo, M. (2016). The effect of the classroom climate, students' attitudes, and perceptions on math toward the association material learning outcomes through students'motivation of class vii SMP in the district of kolaka. Journal of Mathematics Education, 1(2 July), 39-45.

Taylor, R. D., Oberle, E., Durlak, J. A., \& Weissberg, R. P. (2017). Promoting positive youth development through school-based social and emotional learning interventions: A metaanalysis of follow-up effects. Child Development, 88(4), 1156-1171.

Tol, W. A., Song, S., \& Jordans, M. J. (2013). Annual research review: Resilience and mental health in children and adolescents living in areas of armed conflict-a systematic review of findings in low-and middle-income countries. Journal of Child Psychology and Psychiatry, 54(4), 445-460.

Vissing, Y. M., Straus, M. A., Gelles, R. J., \& Harrop, J. W. (1991). Verbal aggression by parents and psychosocial problems of children. Child abuse \& neglect, 15(3), 223-238.

Waheed, I., Batool, S., \& Kausar, R. (2017). Parents' Personality, Family Environment, and Pakistani Adolescents' Personality. Journal of Behavioural Sciences, 27(1), 38-56

Weinberg, R. S., \& Gould, D. (2018). Foundations of sport and exercise psychology, 7E. Human Kinetics. 